\title{
The Helping for Blood-Letting
}

\author{
Dechwit Worasayan*
}

Department of Medicine, Chonburi Regional Hospital, Muang, Chonburi, Thailand

\begin{abstract}
During the hard period of previous two years of political confliction in Thailand, the group of people who were against Thai government represented a symbol of protest by letting their blood to pour various landmarks in Thailand. They wanted to see the prime minister and the government resigned, and the parliament dissolved. The protest leaders who created this idea asked some volunteer physicians to obtain the blood collection. This report aimed to describe and explore the ethical dilemma of blood letting procedure.
\end{abstract}

Keyword: Blood-letting, ethics, protest.

In the past, many people believed that blood-letting can prevent and treat all diseases by elimination of waste products from our body which was similar to woman's menstruation [1]. The physicians in that time apparently knew about the structure and the system of our blood circulation from doing blood-letting. Regarding this belief many doctors in their treatment and barbers in their barbershops performed blood-letting to promote people's health. Therefore, red and white striped pole was subsequently used as a symbol of barbershop until now and they have also built some machines that help to precede this operation more conveniently [2]. In addition, some people have used animal as a tool to obtain this procedure, using the leeches. Blood-letting was used worldwide as disease therapy and was also recommended in ancient standard textbook as frontline disease treatment in that time [3]. The issue of bloodletting was changed after the medical knowledge and technique has developed, the current indications of bloodletting are blood donation, blood test and treatment of some diseases such as primary hemochromatosis, polycythemia vera and porphyria cutanea tarda. Moreover, Mayan culture performs this procedure to sacrifice their gods [4] and aimed to form the unity of people in those countries, and promoted a political strength of their state.

A dilemma of Thai medical procedure was established in March, 2010, the period of the rally of Thai government protester (Red Shirt). This situation seemed not to contribute the unity of nation likewise Maya culture. They shed their blood as a symbolic sacrifice to compel the current Thai prime minister to resign, to dissolve the parliament and to operate a new election. They stated that the current government was illegal and was supported by Thai army. They believe that this anti-democratic force has overlooked the majority of those who have the right to vote. The protest leader proposed that their bloodletting and pouring their blood on Government House's doors were the significant symbols of government protest. They wished that this manner would scare

*Address correspondence to this author at the Department of Medicine, Chonburi Regional Hospital, Muang, Chonburi 20000, Thailand; Tel: +6638_391101; Fax: +6638_391102;

E-mail: dworasayan@yahoo.com the cabinet during they walk over the blood on the floor. Moreover, they poured the blood on the floor outside the Democratic Party's office, which is the leading party of current cabinet, and also poured and spattered the prime minister's house [5]. Protest leaders who created this idea asked some volunteer physicians to obtain the blood collection, they requested the doctors for doing this procedure because it was safe for red shirt protesters and they needed a large amount of blood. In addition, they wanted to show that some doctors were also included in the team of red shirt protesters. The red shirt protesters were the only protesters around the world that time to adopt this procedure to protest. There were some doctors, nurses and medical technicians who were red shirt protesters performing bloodletting, they extract blood by using needle and syringe as a blood donation method. The blood drawn each $10 \mathrm{cc}$ per a protester was mixed together with anticoagulant in many non sterile bottles and gallons. This was a controversial ethical issue between supporters and defenders about the medical right to do bloodletting. Quite surely, the protesters still intensely sacrify and might request to operate bloodletting improperly in the future. The supporters claimed that asking an experienced physician to help venipuncture would be beneficial to prevent them from practice harm. The protesters who donated their blood automatically consented by their action; willing to bleed by their right upon autonomy. In this situation, they used this way to achieve their aim of protest. The code of ethics for nurse labeled that "the nurse would promote, advocates for, and strives to protect the health, safety, and rights of the patient [6]. Doubtfully, did their help save this goal. Physicians should do their practice as the best regardless of any differences of patients including political belief [7]. The question is if the protesters asked you for a fovor, although you disagree with their political faith, would you help them by neglecting their purpose? On the contrary, some people opposed that this was an immoral practice. A declaration of The Medical Technology Council of Thailand occurred in the meantime of this situation asking some responsiveness to this dilemma pertaining to the objectives that blood puncture should only be for disease diagnosis, disease treatment, blood donation and health research [8]. On TV broadcasting, some of the 'so-called' medical professionals 
who assisted this procedure were among the mob dressed red shirts but there was no proof that whether they had the same political faith with their clients or not. Therefore, there was an argument that physician should not deceive or persuade patients to receive services for their advantages in the success of political aim [7]. Since there was no previous medical practice reference for guiding the way to solve this critical situation, therefore it leads to some confrontations to an indefinite ethical prespective especially of political conflictions in Thailand, which are still there and have not seen any termination in Thailand as yet. I suggest that all of the medical professionals should not participate in this operation to pour or splash blood on the places, such as buildings, streets or even on people as this foolish behavior may increase the risk of infection to other people exposed to blood. They should present their intentions themselves without any physicians' helping hands in this situation that could be recognized as a candid performance. The protesters should regard themselves to seek more beneficial way. If they still want to sacrify the blood, consideration of blood donations for patients in hospitals is the best way. They should declare first that this is a symbolic political protest but with an aim. The establishment of the Thai professional council's decision to prohibit this dilemma in the future is absolutely important but still very difficult to accept among the whole Thai public due to the continuing political conflict. We still have a hope for any courageous decisions proposed as the principals and accepted internationally.

\section{REFERENCES}

[1] Gilbert RS. Bloodletting over the Centuries. NY State J Med 1980; 80(13): 2022-8.

[2] Google search as "blood letting" Retrieved at September 12, 2010 from http://en.wikipedia.org/wiki/Bloodletting

[3] Parapia LA. History of bloodletting by phlebotomy. Br J Haematol 2008; 143; 490-5.

[4] Montero Lopez C. Sacrifice and feasting among the classic Maya elite, and the importance of the white-tailed deer: is there a regional pattern? J Hist Eur Stud 2009; 2; 53-68.

[5] Thai protesters collect blood for message. CNN world March 16,2010 Retrieved at September 13,2010 from http://articles.cnn. com/2010-03-16/world/thailand.protests_1_prime-minister-thaksinshinawatra-demonstrators-protesters?_s=PM:WORLD

[6] Code of Ethics for Nurses Approved Provisions 2001, The American Nurse Association. Retrieved at March 19, 2010 from http:// nursingworld.org/ethics/code/protected nwcoe813.htm\#3.5

[7] Regulations of Professional Ethics of Medicine 1983, The Medical Council of Thailand. Retrieved at March 20, 2010 from http:// www.tmc.or.th/service_law02_1.php

[8] Declaration of The Medical Technology Council of Thailand about purposes of blood punctures according to The Act of medical technician of Thailand 2004, March 16, 2010. Retrieved from http:// www.amtt.org/?components=amtt_content\&file $=35$ 